\title{
Laser Technology of Designing Nanocomposite Implants of the Knee Ligaments
}

\author{
A.Yu. Gerasimenko, U.E. Kurilova, M.V. Mezentseva, \\ S.A. Oshkukov, V.M. Podgaetskii, I.A. Suetina, V.V. Zar \\ and N.N. Zhurbina
}

\begin{abstract}
We describe a laser method for constructing a biocompatible implant of the knee ligaments based on synthetic-braided fiber structure of polyethylene terephthalate (PET) coated with a nanocomposite coating. A coating based on albumin aqueous dispersion of carbon nanotubes (CNTs) was applied to the synthetic fibers using ultrasound and then formed by laser evaporation of the aqueous dispersion component. The structure of the nanocomposite implants was studied by optical and atomic force microscopy. Composite implant based on single-walled CNTs (SWCNTs) contains pores with a diameter of 10-20 nm, and based on multi-walled CNTs (MWCNTs) - 40-60 nm. We conducted in vitro studies of proliferative activity of human fibroblast cells $(\mathrm{HFb})$ during their colonization on
\end{abstract}

\footnotetext{
A.Yu. Gerasimenko ( $ه)$ · U.E. Kurilova · V.M. Podgaetskii · N.N. Zhurbina

Biomedical Systems Department, National Research University

of Electronic Technology, Moscow, Russia

e-mail: gerasimenko@bms.zone

U.E. Kurilova

e-mail: kurilova_10@mail.ru

V.M. Podgaetskii

e-mail: podgaetsky@ya.ru
}

N.N. Zhurbina

e-mail: Natalia93Zhurbina@gmail.com

M.V. Mezentseva · I.A. Suetina

Tissue Culture Laboratory, Ivanovsky Institute of Virology,

Moscow, Russia

e-mail: marmez@mail.ru

\section{I.A. Suetina}

e-mail: ikas@inbox.ru

S.A. Oshkukov · V.V. Zar

Trauma Department, M. Vladimirsky Moscow Regional Research

Clinical Institute, Moscow, Russia

e-mail: sergey0687@mail.ru

V.V. Zar

e-mail: vzar66@gmail.com 
the surface of the implant and into the space between synthetic fibers. The highest value of the $\mathrm{HFb}$ proliferation was observed on the implant based on MWCNTs with a large pore size and amounted to 55.435 pcs., in contrast to the implant based on SWCNTs (54.931 pcs.) and control one (54.715 pcs.), as shown by fluorescence microscopy and MTT test. A histological study of the interaction of the nanocomposite implant implanted into rabbit knee joint with bone canal was carried out. The bone germination in the implantation area at 2, 4 and 8 weeks after surgery was shown.

Keywords Knee ligament implant $\cdot$ Nanocomposite material $\cdot$ Bioengineering Carbon nanotubes · Bovine serum albumin $\cdot$ Laser structuring $\cdot$ Scaffold Cells · Microscopy

\section{Introduction}

Injuries of the intraarticular knee joint ligaments (KJL) constitute one of the best-studied problems in contemporary orthopedics. This relates to the high incidence of these injuries and their social importance. In the USA, isolated injuries of the anterior cruciate ligament in the knee occur in 43 cases per 100,000 of the population per year and have increased significantly in the under $20 \mathrm{~s}$ and middle-aged women [6]. In Germany, every traumatologist performs an average of 35 knee joint ligament reconstructions per year [11]. Data from Russian medical institutions show that the incidence of ligament injuries is one case per 3000 of the population, most patients being active working people aged 16-45 years.

One important cause of unsatisfactory surgical outcomes for these injuries is the poor biological integration of bone channel wall tissues into ligament implants [5]. Knee joint ligament implants are usually developed using synthetic-braided materials as flat ribbons or seamless tubes made of polyethylene terephthalate (PET) fibers. Advantages of using PET include its resistance to the acidic and alkaline environments of the body and to mechanical damage. This material has a density of 1360 $1400 \mathrm{~kg} / \mathrm{m}^{3}$ and a breaking point on stretching of $172 \mathrm{MPa}$. However, the strength characteristics of braided PET fibers is much higher than the strength of the canal's bone tissue, in which the implant is fixed. Therefore there is the problem of destruction of the bone canal surface, particularly at the first time after the operation.

Contemporary regenerative methods are being used to overcome this problem, specifically tissue engineering, which is the method of partial or complete restoration of the physical and biological functions of injured or lost organs by stimulating regeneration of the three-dimensional tissue structure [8]. This method is conceptually based on creating artificial tissue-engineered scaffolds to support cell proliferation and maintain the growth of biological tissues [9]. In order to fulfill their function, scaffolds must be biocompatible and biodegradable, must have a porous structure, and must have mechanical characteristics corresponding to specific biological tissues [2]. 
Carbon nanotubes (CNT) distributed in a biological matrix are one of the perspective materials for creating of tissue-engineered scaffolds [1, 4, 7]. These scaffolds are potential materials for solving the problem of KJL restoration by below described method of constructing biocompatible knee ligament implants when nanocomposite coatings are formed on the PET fibers surface. The coating based on tissue-engineered scaffolds of CNTs in protein matrix provides the best adhesion and cell growth of connective and bone tissues, which can lead to reduction of a postoperative recovery period of patients.

\section{Materials and Methods}

The method of the nanocomposite coating forming on PET fibers involves three steps. The first step consists of preparing a homogeneous dispersion of CNTs in the protein matrix. We used two types of nanotubes: single-walled carbon nanotubes (SWCNTs) and multi-walled carbon nanotubes (MWCNTs) with purity of $98 \%$. SWCNTs were synthesized by an electric arc method on a Ni/Y catalyst and are presented as a black paste in deionized water (concentration is $\sim 2.5 \%$ by weight). The mean diameter of SWCNTs was $\sim 1.5 \mathrm{~nm}$ and length was $0.5-1.5 \mathrm{~nm}$. Nanotubes were aggregate as filaments with mean length $1-10 \mu \mathrm{m}$ and cross-sectional diameters of $67 \mathrm{~nm}$ [10]. MWCNTs were synthesized by a low-temperature thermo-catalytic method on a Ni catalyst and consisted of a black powder. The external diameter of MWCNTs was 40-120 nm, length was 1-10 $\mu \mathrm{m}$, and internal diameter was $10-30 \mathrm{~nm}$ [3]. As the technology for coatings making requires thermal heating of the dispersion, bovine serum albumin (BSA) was selected as a protein with maximal resistance to temperatures. The purity of the BSA was $98.1 \%$ by weight and the heavy metals content was no greater than $0.001 \%$ by weight.

Apparatus for forming nanocomposite coating on synthetic construction is illustrated in Fig. 1. The mass proportions of the components of the dispersion were weighed out on an analytical balance (1) and were $0.02-0.1 \%$ CNTs, $25 \%$ for BSA, and $74.98-74.9 \%$ for water. CNTs were initially mixed in water with a magnetic

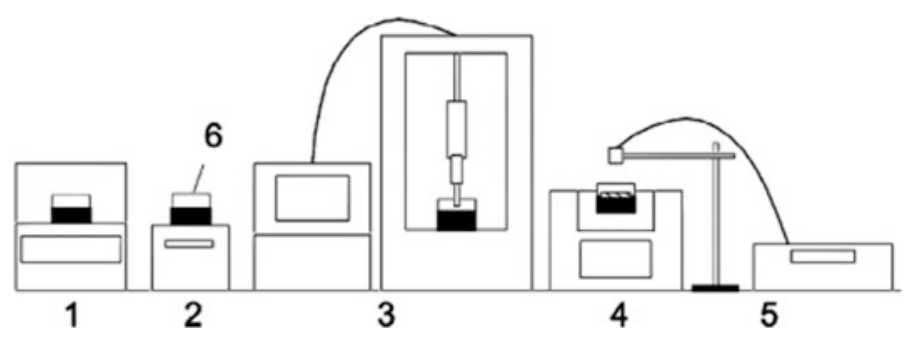

Fig. 1 Apparatus for forming composite coatings on synthetic PETF fiber constructs (see text for explanation) 
stirrer (2) and ultrasound homogenizer (3) at a power level of $40 \mathrm{~W} / \mathrm{cm}^{2}$ to prepare a homogeneous dispersion of CNTs in water, as the presence of nanotube agglomerates would lead to an inhomogeneous coating. The CNTs dispersion was then supplemented with powder of BSA, and the mixture was processed gently with a magnetic stirrer (2) and an ultrasound bath (4) at a power of $2 \mathrm{~W} / \mathrm{cm}^{2}$.

The second step in forming the composite nanocoating consisted of ultrasound application of the dispersion, prepared in the first step, to the surface of PET fibers braided as a flat ribbon or tubular constructs. The synthetic construct was placed in a vessel with the dispersion (6), placed in an ultrasound bath with liquid, such that the levels of the dispersion and the liquid were the same. Ultrasound treatment was at a power of $1-2 \mathrm{~W} / \mathrm{cm}^{2}$ for $10 \mathrm{~min}$. At the third step, the dispersion was removed from the vessel containing the synthetic construct and the dispersion on PET surface was treated by uniform laser radiation. Irradiation was with a continuous infrared diode laser (5) at a wavelength of $810 \mathrm{~nm}$ and a power level of $35 \mathrm{~W}$. The spatial profile of the laser beam had a Gaussian distribution and its diameter was comparable to the width of the synthetic construct.

Figure 2 shows images of the structure of a synthetic construct bearing an MWCNTs-based dispersion (Fig. 2a, b) or an SWCNTs-based dispersion (Fig. 2c, d) produced by optical microscopy at magnifications of $\times 40$ (Fig. 2 a, c) and $\times 5$ (Fig. 2b, d).

(a)

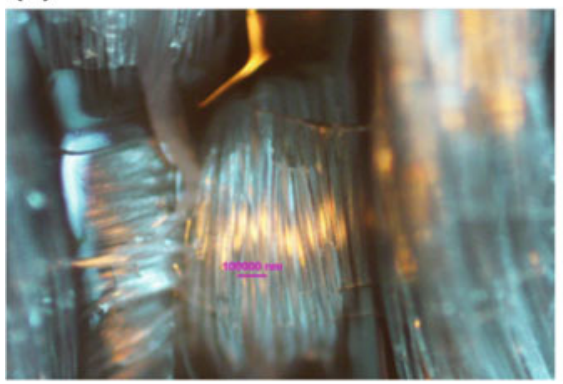

(c)

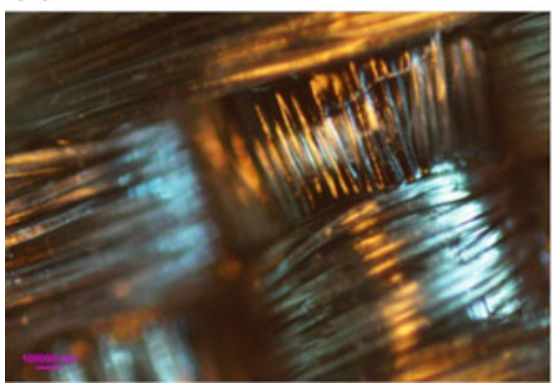

(b)

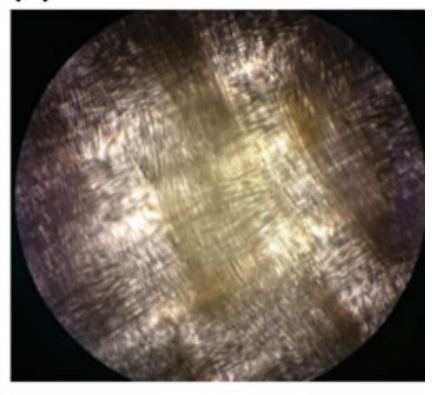

(d)

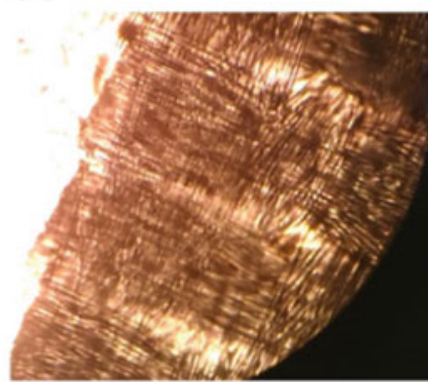

Fig. 2 Optical microscope images of nanocomposite coating with composite nanocoatings based on MWCNT $(\mathbf{a}, \mathbf{b})$ and SWCNT $(\mathbf{c}, \mathbf{d})$ 
The ultrasound method of applying the nanocarbon dispersion generated a uniform coating on the surface of the synthetic construct. The aqueous component of the dispersion was evaporated during the laser treatment. Under the influence of electric field of the targeted laser irradiation organization of the nanotubes, scaffold was carried out in synthetic construct coating.

Figure 2 shows that the SWCNTs-based composite nanocoating on PET fibers had a more uniform light gray coloration than the MWCNTs-based coating. This may be due to the presence of hydrophilic functional groups on the nanotube surfaces, resulting in better homogenization in the aqueous matrix.

Because of the evaporation of water, large numbers of pores were seen throughout the volume of the scaffold, these being needed for adhesion of cellular material (Fig. 3). Form and quantity of pores depend on manufacturing process parameters. Basically, CNTs adding to BSA matrix resulted in decreasing of pores quantity and size. This effect can be due to reinforcing the action of CNTs when the scaffold is formed by laser irradiation. An average size of scaffold nanoelements was less than $500 \mathrm{~nm}$, a volume density was in the range $10^{6}-10^{8} \mathrm{~cm}^{-3}$.

(a)

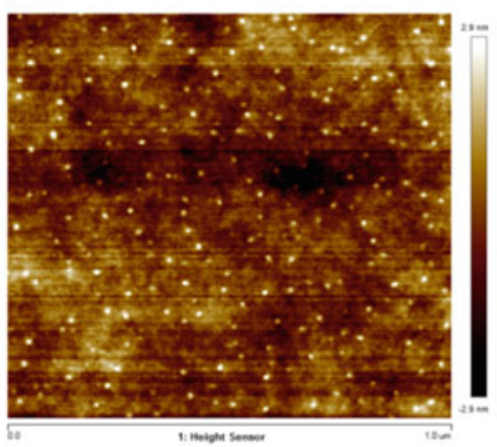

(c)

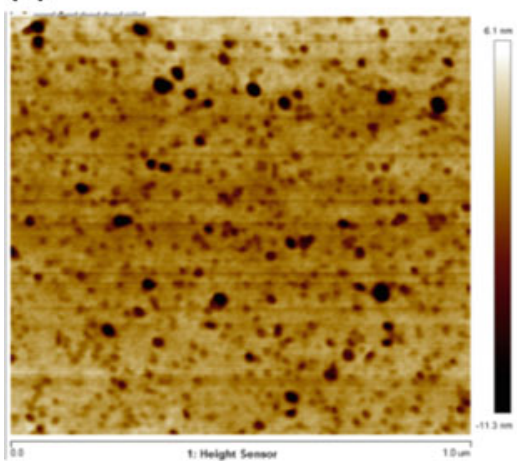

(b)

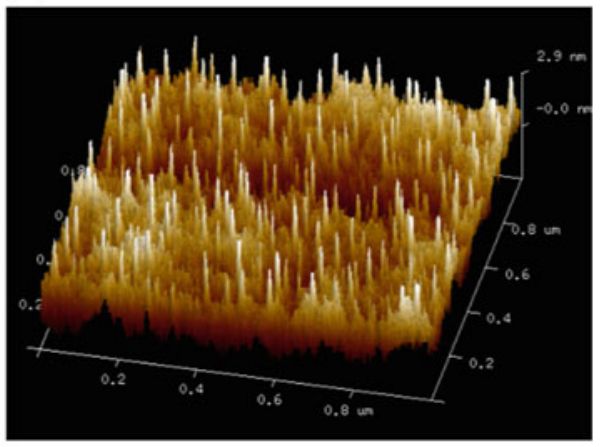

(d)

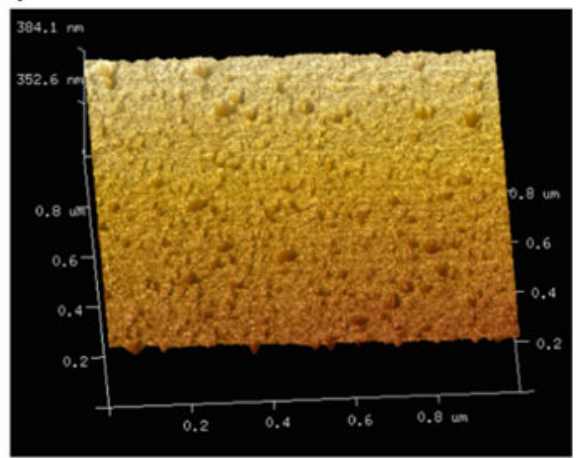

Fig. 3 2-D (a, c) and 3-D (b, d) AFM topograms of the composite coating, based on SWCNT $(\mathbf{a}, \mathbf{b})$ and MWCNT $(\mathbf{c}, \mathbf{d})$ formed by the laser irradiation 
Detailed studies of the porosity of the samples by capillary adsorption-desorption of nitrogen yielded the following results. Mean pore diameter for SWCNTs-based samples was 10-20 nm, while the value for MWCNTs-based samples was almost three times greater, at 40-60 $\mathrm{nm}$. Specific pore volume in the SWCNTs-based sample was greater $(0.005 \mathrm{ml} / \mathrm{g})$ than in MWCNT-based samples $(0.0033 \mathrm{ml} / \mathrm{g})$.

\section{Results}

The biological characteristics of the synthetic constructs with nanocomposite coatings were assessed by studying the proliferative activity of connective tissue cells - human fibroblasts $(\mathrm{HFb})$ - in the presence of samples. Samples were fragments of synthetic constructs of size $1 \times 1 \mathrm{~cm}$ with and without nanocomposite coatings.

Prepared samples were sterilized by UV irradiation for $1 \mathrm{~h}$. HFb cells were cultured with experimental samples and then incubated in DMEM (Dulbecco's Modified Eagle's Medium) supplemented with $10 \%$ fetal calf serum. Incubation was in culture plates in an incubator at $37{ }^{\circ} \mathrm{C}$ for $72 \mathrm{~h}$ in a moisture-saturated atmosphere containing $5 \% \mathrm{CO}_{2}$.

Colonization of $\mathrm{HFb}$ cells occurred on the surfaces and between the PET fibers and was assessed by fluorescence microscopy. Cells on samples of synthetic constructs were treated with fluorescein diacetate (FDA) to a final concentration of $25 \mu \mathrm{g} / \mathrm{ml}$ and then with ethidium bromide (EtBr) to a final concentration of $1 \mu \mathrm{g} / \mathrm{ml}$ with incubation during $5 \mathrm{~min}$ at $37^{\circ} \mathrm{C}$. Cells were then washed three times with medium without calf serum and were examined by an Olympus BX43 fluorescence microscope with a TRITC (CY3) red-orange filter. The resulting images were converted to grayscale images, which showed staining nuclei of $\mathrm{HFb}$ on the surface of the sample and between the PET fibers (Fig. 4).

Sequential analysis of the whole sample surface led to the conclusion that cell proliferative activity occurred in all samples. Figure 3 shows, that the greatest level of cell activity was seen in $24 \mathrm{~h}$ after incubation. The largest number of cells was colonized on samples of the synthetic construct with the SWCNTs-based nanocomposite coating, though the distributions of cells over all samples were inhomogeneous and did not differ greatly. There was a decrease in HFb proliferative activity at $96 \mathrm{~h}$ of incubation, larger numbers of cells were presented on the sample with the MWCNTs-based coating. Smaller numbers of cells for the two incubation periods were seen on the uncoated sample.

The proliferative activity of $\mathrm{HFb}$ cells was assessed using the photocolorimetric MTT test [12]. The MTT test consists of staining living cells with crystals of yellow tetrazole (MTT), which they reduce to purple formazan. Analysis of the optical density of the resulting medium assesses the viability of cells colonizing the constructs and, thus, its cytotoxicity. 
(a)

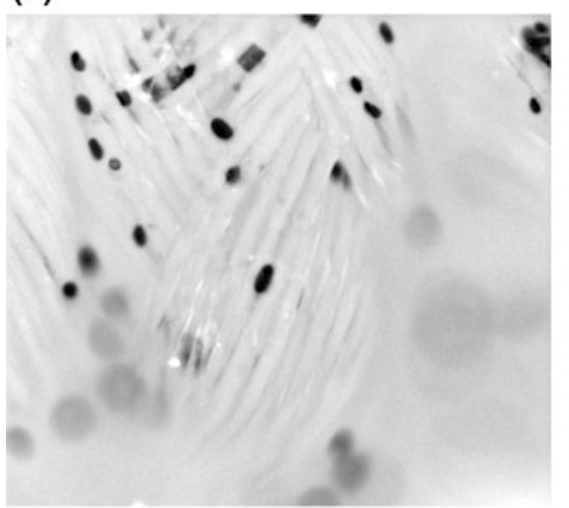

(c)

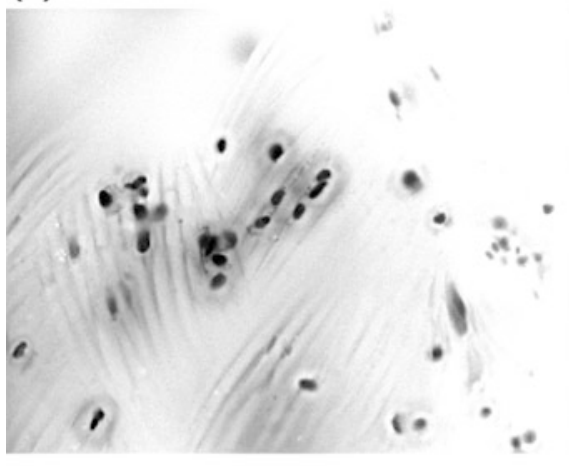

(e)

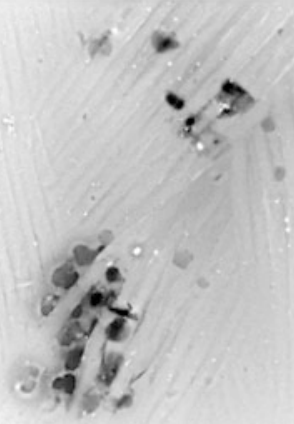

(b)
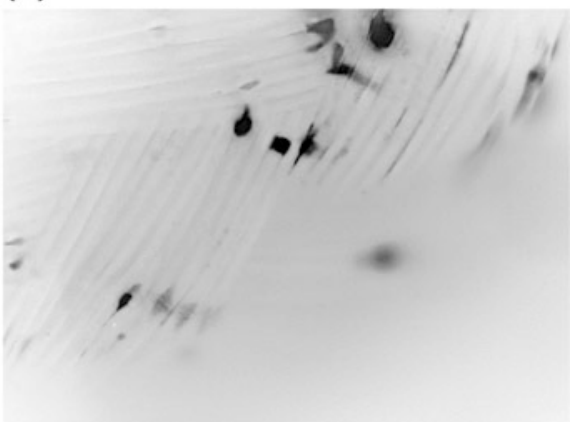

(d)

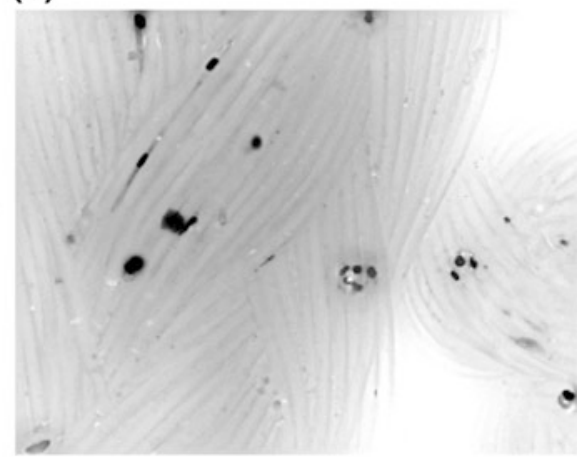

(f)

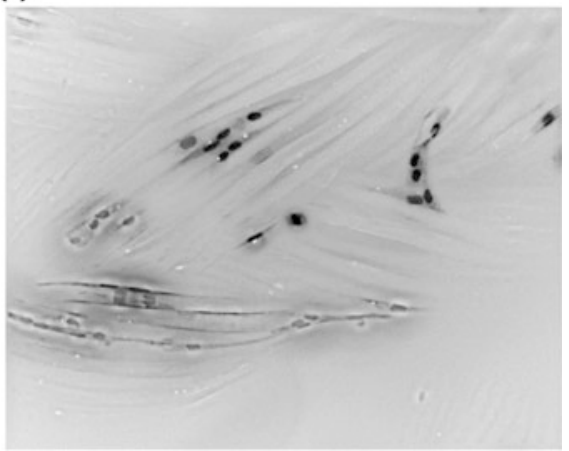

Fig. 4 Fluorescence microscope images of stained $\mathrm{HFb}$ colonizing the surfaces and between the PETF fibers of synthetic constructs $(\mathbf{a}, \mathbf{b})$ and constructs with nanocomposite coatings based on SWCNTs (c, d) and MCWNTs (e, f) at $24(\mathbf{a}, \mathbf{c}, \mathbf{e})$ and $96 \mathrm{~h}(\mathbf{b}, \mathbf{d}, \mathbf{f})$ of cell incubation 
The numbers of cells proliferated on samples were evaluated by adding MTT solution to the culture medium to a final concentration of $0.25 \mathrm{mg} / \mathrm{ml}$. $3 \mathrm{~h}$ of incubation was followed by removal of the culture medium and washing of the cells with phosphate-buffered saline. Samples were then supplemented with $100 \mu \mathrm{l}$ of dimethyl sulfoxide and incubated for a further $30 \mathrm{~min}$. This method allows complete extraction of dye from the cells. Determination of the absolute number of $\mathrm{HFb}$ was run on a Scepter 2.0 counter with sensor tips.

Optical densities were measured using an Immunochem-2100 microplate photometer. Excitation was at $545 \mathrm{~nm}$, which is corresponding to the first absorption peak of the MTT spectrum. Figure 5 shows mean optical densities for experimental samples of the synthetic constructs with nanocomposite coatings based on SWCNTs (2) or MWCNTs (3) and an uncoated control sample (1). Figure 5 shows that the greatest level of cell proliferation was seen on samples of synthetic constructs with nanocomposite coatings. HFb growth on samples with SWCNTs- and MWCNTs-based coatings reached 54,931 and 55,435 HFb cells, respectively, compared with 54,715 cells on the control sample. The MWCNTs-based coating provided the best cell growth. These data are clearly linked with a tendency for the cell processes of fibroblasts to attach to the most porous surface coating based on MWCNTs. Cell viability on samples bearing the SWCNTs-based coating was $2.7 \%$ greater than that on the uncoated sample, while cell viability on constructs with the MWCNTs-based coating exceeded the uncoated sample by $8 \%$. This result points to the ability of nanocomposite coatings to provide the best cell adhesion and growth.

To study the interaction between nanocomposite implant and bone canal, we carried out a surgery to insert the implant into rabbit knee joint. Then we estimated interaction of the implant material with surrounding tissues by histological studies. Four Russian Giant rabbits were selected as biological models. Anesthesia was made before surgery by an intravenous injection. Then the depilation of hair in the area of the left and right knee joints was performed. Through bone canal $2-5 \mathrm{~mm}$ in length and $4.5 \mathrm{~mm}$ in diameter was formed in the right knee joint of each animal by surgical method. Nanocomposite implant was introduced in the bone canal, and the bone canal

Fig. 5 Mean optical densities of samples of synthetic constructs (1) and constructs bearing nanocomposite coatings based on SWCNT (2) and MWCNT (3)

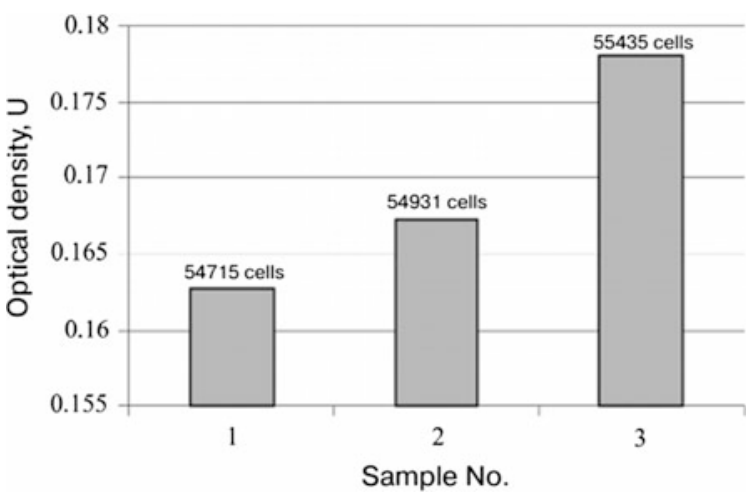


was filled by water-protein CNTs dispersion and treated by laser radiation with the temperature not higher than $55^{\circ} \mathrm{C}$ to evaporation of the water component.

At the end of the operation, the incision was closed with sutures. The left knee joint of each animal was used as a control, and we inserted and secured there the commercial version of the traditional tape for ligament replacement with identical geometrical dimensions to experimental joint. Removing animals from the experiment was carried out at 2, 4, and 8 weeks, followed by preparation for histological research. Histological sections were made using microtome. Slice thickness was 5-10 microns. Sections of the samples were placed on a slide and stained with hematoxylin-eosin dye.

We observed bone tissue with the adjoined implanted artificial fiber material, on all histological sections. Two weeks after the implantation, there was no bone response in experimental and control samples (Fig. 6a, b). After 4 weeks, the test specimen had a moderate lobular proliferation of immature cellular fibrous tissue (Fig. 6c). In the control sample (Fig. 6d) obvious proliferation of immature cellular fibrous tissue was detected. After 8 weeks, the control sample had an obvious proliferation of immature cellular fibrous tissue with small areas of bone formation and small focal calcification (Fig. 6d). The test specimen had a proliferation of immature cellular fibrous tissue with areas of mature fibrous tissue and obvious bone formation and focal calcification (Fig. 6e).

\section{Conclusions}

A method for making knee joint ligament implants based on synthetic constructs made of PET fibers bearing nanocomposite coatings was developed. The coatings consisted of water-albumin dispersions of CNTs and were applied to the synthetic fibers using ultrasound. Coatings were fixed by laser evaporation of the liquid component of dispersion. The electric field of the irradiation promoted self-organization of the nanotubes on the scaffold. Evaporation of the liquid led to the formation of pores in the coating, and mean pore diameters for SWCNTs-based samples were 10-20 nm, compared with 40-60 nm for MWCNTs-based samples. In vitro studies of the activity of HFb cells, colonized on the surface and between the synthetic fibers, showed that a higher level of $\mathrm{HFb}$ proliferation was seen on samples of synthetic constructs with composite coatings based on MWCNTs. MTT test demonstrated, that cells amount in this sample was about 55,435 cells, which is a lot more than on SWCNTs-based coatings and control samples. Thus, these results lead to the conclusion that fibroblast adhesion and growth are better on the MWCNTs-based composite coatings, which has a greater pore size than the other samples.

After nanocomposite implants implantation in rabbit knee joints, there was a pronounced proliferation of immature cellular fibrous tissue with lots of mature fibrous tissue and obvious osteogenesis unlike control sample in 8 weeks. As a 
(a)

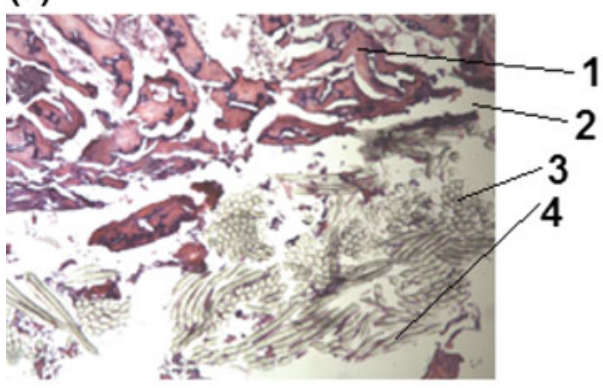

(c)

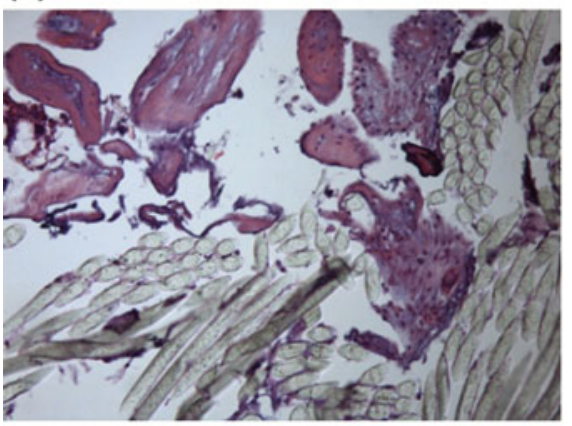

(e)

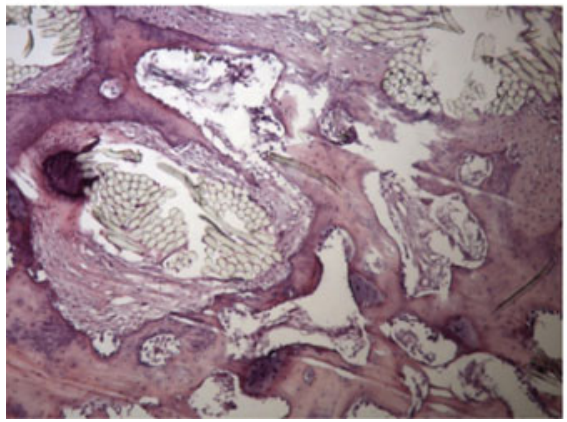

(b)

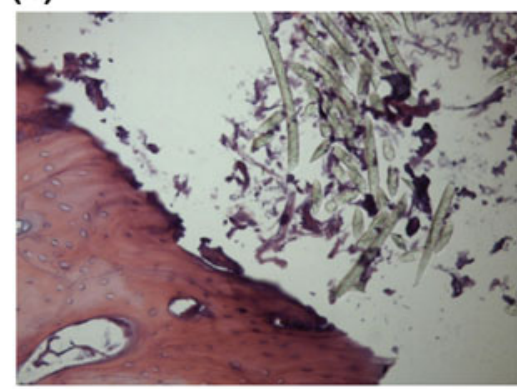

(d)

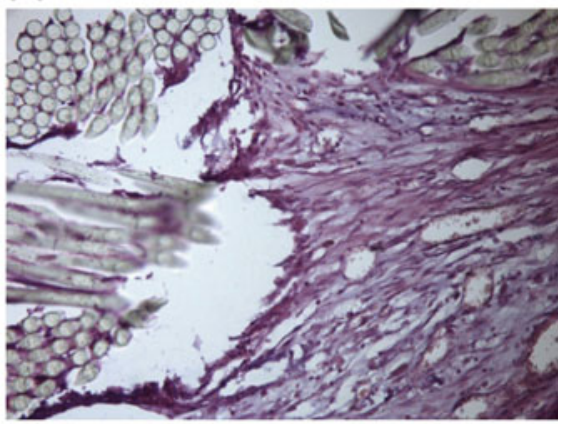

(f)

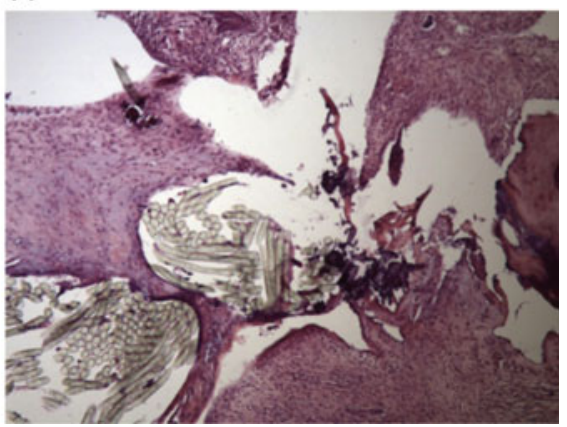

1- bone tissue; 2- empty space; 3- cross section of a synthetic fiber structure; 4- longitudinal section of a synthetic fiber structure

Fig. 6 Histological sections of nanocomposite implant in the bone canal. Magnification of $\times 100$ $(\mathbf{a}, \mathbf{e}, \mathbf{f})$, and $\times 200$ (b-d). Animal No 1 (a), control in 2 weeks (b). Animal No 2 (c), control in 4 weeks (d). Animal No 3 (e), control in 8 weeks (f) 
result, the studied nanocomposite implants provide high osteoconductivity and can be used for the reconstruction of the knee ligaments.

Acknowledgements Research is carried out with the financial support of the state represented by the Ministry of Education and Science of the Russian Federation. Agreement no. 14.575.21.0089 21.Oct 2014. Unique project Identifier: RFMEFI57514X0089.

\section{References}

1. Abattategi, A., Gutierrez, M.C., Moreno-Vicente, C., Hortiguela, M.J., Ramos, V., Lopes-Lacomba, J.L., Ferrer, M.L., Monte, F.: Multiwall carbon nanotube scaffolds for tissue engineering purposes. Biomaterials 29, 94-102 (2008)

2. Fomin, A., Dorozhkin, S., Fomina, M., Koshuro, V., Rodionov, I., Zakharevich, A., Petrova, N., Skaptsov, A.: Composition, structure and mechanical properties of the titanium surface after induction heat treatment followed by modification with hydroxyapatite nanoparticles. Ceram. Int. 42(9), 10838-10846 (2016)

3. Gerasimenko, A.Yu., Ichkitidze, L.P., Podgaetsky, V.M., Savelyev, M.S., Selishchev, S.V.: Laser nanostructuring 3-D bioconstruction based on carbon nanotubes in a water matrix of albumin. Proc. SPIE 9887, 988725-1-988725-10 (2016)

4. Hirata, E., et al.: Development of a 3D collagen scaffold coated with multiwalled carbon nanotubes. J. Biomed. Mater. Res. B: Appl. Biomater. 90(2), 629-634 (2009)

5. Jiang, J., Wan, F., Yang, J., Hao, W., Wang, Y., Yao, J., Shao, Z., Zhang, P., Chen, J., Zhou, L., Chen, S.: Enhancement of oseointegration of polyethylene terephthalate artificial ligament by coating of silk fibroin and depositing of hydroxyapatite. Int. J. Nanomed. 9, 804569 (2014)

6. Mall, N.A., Chalmers, P.N., Moric, M., Tanaka, M.J., Cole, B.J., Bach, B.R., Paletta, G.A.: Incidence and trends of anterior cruciate ligament reconstruction in the United States. Am. J. Sports Med. 42(10), 70-2363 (2014)

7. Martino, A., Sittinger, M., Risbud, M.V.: Chitosan: a versatile biopolymer for orthopaedic tissue-engineering. Biomaterials 26(30), 5983-5990 (2005)

8. Mooney, D.J., Mikos, A.G.: Growing new organs. Sci. Am. 280, 38-43 (1999)

9. Peters, M.C., Mooney, D.J.: Synthetic extracellular matrices for cell transplantation. Mater. Sci. Forum. 250, 43-52 (1997)

10. Podgaetsky, V.M., Selishchev, S.V., Bobrinetskii, I.I., Nevolin, V.K.: Volumetric nanodesign by new laser method. Application for medical purposes. Opt. Mem. Neural Netw. (Information Optics) 17(2), 147-151 (2008)

11. Shafizadeh, S., Jaecker, V., Otchwemah, R., Banerjee, M., Naendrup, J.H.: Current status of ACL reconstruction in Germany. Arch. Orthop. Trauma. Surg. 136(5), 593-603 (2016)

12. Wilson A.P.: Chapter 7: Cytotoxicity and viability. In: Masters, J.R.W. (ed.) Animal Cell Culture: A Practical Approach, vol. 1, 3rd. edn. Oxford: Oxford University Press (2000) 
Open Access This chapter is licensed under the terms of the Creative Commons Attribution 4.0 International License (http://creativecommons.org/licenses/by/4.0/), which permits use, sharing, adaptation, distribution and reproduction in any medium or format, as long as you give appropriate credit to the original author(s) and the source, provide a link to the Creative Commons license and indicate if changes were made.

The images or other third party material in this chapter are included in the chapter's Creative Commons license, unless indicated otherwise in a credit line to the material. If material is not included in the chapter's Creative Commons license and your intended use is not permitted by statutory regulation or exceeds the permitted use, you will need to obtain permission directly from the copyright holder.

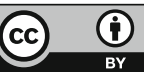

